\title{
The Effects on Sick Leave of Changes in the Sickness Insurance System*
}

\author{
by \\ Magnus Henrekson ${ }^{1 \ddagger}$ and Mats Persson ${ }^{2}$ \\ SSE/EFI Working Paper Series in Economics and Finance No 444
}

Revised March 17, 2003

\begin{abstract}
In order to get a more complete picture of how labor supply is affected by economic incentives, the effects on absenteeism and not just on contracted hours should be taken into account. In particular, absenteeism due to sick leave can be considerable. In this paper we examine whether the level of sick leave compensation affects sick leave behavior. Using time-series data for Sweden spanning a long period (1955-99) with numerous changes of the compensation level, we generally find strong effects of the expected sign. Reforms implying more generous compensation for sick leave tend to be associated with permanent increases in total sick leave per person employed and vice versa. These findings are reinforced in a panel study covering the 1983-91 period.
\end{abstract}

JEL Classification: H55, I38, J22.

Keywords: Absenteeism, Labor supply, Sick leave, Sickness insurance, Social security.

$\begin{array}{ll}\text { TCorresponding author } & \\ { }^{1} \text { Department of Economics } & { }^{3} \text { Institute of International Economic } \\ \text { Stockholm School of Economics } & \text { Studies, IIES } \\ \text { P. O. Box 6501 } & \text { Stockholm University } \\ \text { S-113 83 Stockholm } & \text { S-106 91 Stockholm } \\ \text { SWEDEN } & \text { SWEDEN } \\ \text { Phone: }+46-8-7369202 & \text { Phone: }+46-8-162224 \\ \text { Fax: }+46-8-313207 & \text { Fax: }+46-8-161443 \\ \text { e-mail: Magnus.Henrekson@hhs.se } & \text { e-mail: } \text { mp@,iies.su.se }\end{array}$

\footnotetext{
* We are grateful for highly valuable econometric advice and help from Dick Durevall and Paolo Giordani. Useful comments and suggestions on earlier drafts have been received from Robin Douhan, Paolo Giordani, Lennart Jonsson, Ulrik Lidwall, Mårten Palme, Peter Skogman Thoursie and Timo Teräsvirta. Most importantly, we owe a great intellectual debt to Kari Lantto who was deeply involved in the initial stage of this project. Financial support from the Jan Wallander and Tom Hedelius Research Foundation is gratefully acknowledged.
} 


\section{Introduction}

Traditional labor supply studies primarily deal with the incentive effects of changes in aftertax wages. Studying only the effects on contracted hours could however be misleading. To get a more complete picture of the determinants of actual hours worked, absenteeism needs to be taken into account. In fact, work absenteeism may be seen as a dual to labor supply problems (Johansson and Brännäs, 1998). In particular, it seems justified to study the incentive effects of different compensation levels for absenteeism on actual hours worked.

Naturally, absence from work can have multiple causes, but there is little doubt that the quantitatively most important one is sick leave. ${ }^{1}$ However, there are relatively few studies of these issues. For example, according to the subject index, the terms "sick leave" and "absenteeism" do not appear at all in the 3,630 pages of the Handbook of Labor Economics. ${ }^{2}$

The quantitative effects of sick leave can be considerable. In Sweden in 1988, the average sick leave per person employed totaled five work weeks per year, i.e., more than 10 percent of total contracted working time. A few years later, this had fallen to three weeks, corresponding to an increase in hours actually worked by close to five percent. If such a large increase in effective labor supply should be achieved by a wage increase, this would, given typical estimates of Swedish labor supply elasticities ${ }^{3}$ of 0.1 , require an after-tax wage hike on the order of 40-50 percent.

The purpose of this paper is to investigate whether the insurance system for sick leave compensation affects sick leave behavior. Earlier studies in this small literature (Barmby, Orme and Treble, 1991, 1995; Drago and Wooden, 1992; Johansson and Palme, 1996, 2002; Johansson and Brännäs, 1998; Broström, Johansson and Palme, 2001; Gilleskie, 1998) use individual cross-section data. The typical setup is to analyze how absenteeism differs across individuals with respect to individual characteristics (age, gender, marital status, part-time work, income et cetera). Economic incentives are captured by the after-tax wage rate, or the difference (or ratio) between the wage rate and the sick-leave compensation. It is notable,

\footnotetext{
${ }^{1}$ Johansson and Palme (1996, p. 196) define work absence as "time when the employee is absent from work, which cannot be referred to as statutory leisure time or absence agreed upon in advance with the employer." They refer to a study showing that 97.1 percent of work absence for blue collar workers in Sweden is covered by the sickness insurance.

2 Vol. 1-3C (1986, 1999), Amsterdam: North-Holland.
} 
however, that the typical study only analyzes one insurance system at a single point in time. The necessary variation in economic incentives is obtained since individuals differ with respect to marginal tax rates, compensation levels, or other aspects of the insurance scheme.

In contrast, we examine long-run time-series of aggregate sick leave behavior in Sweden during the period 1955-99. The variation in economic incentives is obtained by the frequent changes in the insurance system over time. The long time series and the fact that there has been considerable variation in the rules for sick leave compensation during the period makes the Swedish experience particularly useful as a case for testing for the existence of economic incentive effects on sick leave behavior.

The cross-section micro approach has several advantages. For example, provided the sample is large, one can obtain fairly precise estimates of preferences, and thereby fairly reliable forecasts of responses to future changes in the insurance system. There are, however, some drawbacks. First, if reliable estimates of preferences are to be obtained, the statutory benefit rules must give an accurate representation of the individual's decision problem. In reality, it is not the statutory rules themselves, but the agent's perception of the rules that is relevant. But even if the perception is correct, some of the changes in the system do not apply to the broad compensation rates in Table 1, but are more subtle and consist of, e.g., changes in the detection probabilities for those who shirk, or changes in some regions of the budget sets that cannot easily be represented by a few parameters only (cf. footnote 6).

Second, there are interesting time-series issues involved that cannot be properly analyzed by looking at a cross-section of individuals immediately before and after a reform. Some of these issues are related to the difficulty mentioned above of representing the actual decisions problem (for instance, the individuals may not perceive the true changes in the budget sets immediately, but will learn about the new rules over time). At the same time, time-series studies may raise issues of causality and spurious correlation that need to be dealt with. We will return to these issues when discussing our specification of the model, and only note that the understanding of sick-leave behavior is well served by microeconometric cross-section studies as well as by studies of aggregate time series.

\footnotetext{
${ }^{3}$ See Aronsson and Walker (1997) for a survey of Swedish studies.
} 
The paper is organized as follows. In section II we present the data describing the evolution of aggregate sick leave behavior in Sweden from 1955 to 1999 and discuss some limitations in the data. Section III contains a brief characterization of the numerous sick leave compensation schemes during this period. In section IV we discuss problems of causality and present a number of regression analyses using annual data. The regression analyses are taken one step further in section $\mathrm{V}$, where we use a panel of quarterly data to identify possible effects of the 1987 and 1991 reforms. Section VI concludes the paper.

The main finding of our paper is that there appears, in most cases, to be strong effects on sick leave behavior from changes in sick leave compensation levels. Such an effect can be detected both when the system is rendered more generous and when it becomes more restrictive. Furthermore, we detect clear differences across gender and a strong negative effect from increased unemployment.

\section{A First Glance at the Data}

In Sweden there is a large amount of data on sick leave, covering long time periods and widely different insurance systems. The main database is compiled by the National Social Insurance Board (RFV) and gives the average number of sick days per person and year, in a time series from 1955. This series is depicted in Figure 1, where we see that in 1955 paid sick leave averaged 12 days a year. This figure reached a peak in 1988 at 25 days per year, fell sharply during the early 1990s and is now increasing again.

There seems to be a slight upward trend in the data. A simple time-trend regression indicates that the number of sick-leave days increases by 0.08 days per annum over the period, but the trend is barely significant at the 5 percent level.

The RFV data, however, only include sick leave covered by the Swedish national sickness benefit system. From 1955 to 1962, the first two days of a sickness spell were not covered, and from 1962 to 1974 the first day was not covered. These days are thus not included in the data, which means that the diagram slightly underestimates the number of days during the earlier part of the time span. Neither was the first day paid for from 1974 to 1987, but it was possible to circumvent this restriction by reporting sick (to an answering service) before 
midnight the preceding day. Due to lack of data, it is impossible to assess the importance of these deficiencies for the reliability of the time series.

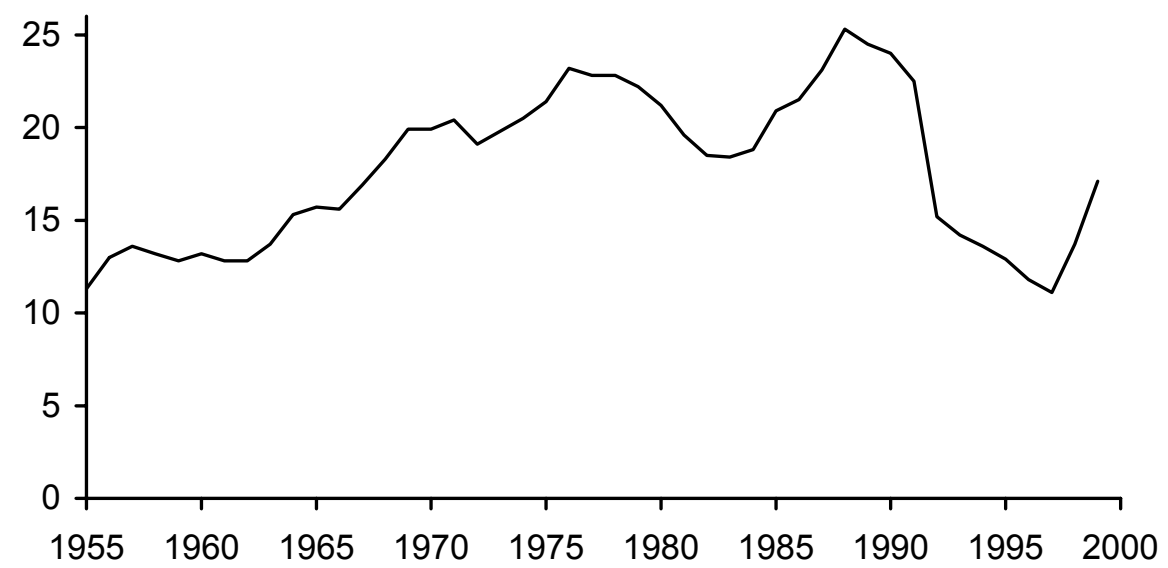

FIG. 1. - Days of paid sick leave according to the RFV database (number of days annually per person, 1955-99).

From December 1987 to December 1991, the national insurance system covered all sickness spells, however short; thus the data in Figure 1 provide full coverage for those years. In the 1990s, various changes in the system were implemented, withdrawn, and re-implemented. The basic feature of the different systems used in the 1990s was that the national system did not cover the first few weeks of a sickness spell. Instead, the initial sickness period was financed by the employers to varying degrees, the idea being to create incentives for the employers to monitor their employees, to improve working conditions, et cetera. All these changes and experiments in the 1990s mean that short-term sickness spells are not included in the RFV data, and thus Figure 1 gives an underestimation of the absenteeism during these years. 
Thanks to other data sources, however, it is possible to correct for this. The Swedish Employers' Confederation (SAF) has compiled a database consisting of a reasonably representative sample covering 2,500 establishments and 220,000 employees in the private sector. In this data set absenteeism due to sickness can be categorized by the length of the sickness spell, and one can identify how many spells that were shorter than a given number of days. ${ }^{4}$ Thus, the numbers missing for the short-term spells in the RFV database can be easily obtained. Assuming that the sickness pattern is the same for the public sector as for the private sector, we have thus corrected the data in Figure 1. The exact procedure used for this correction is described in the Appendix. The corrected time series is shown in Figure 2, where the old time series is shown as a dotted curve.

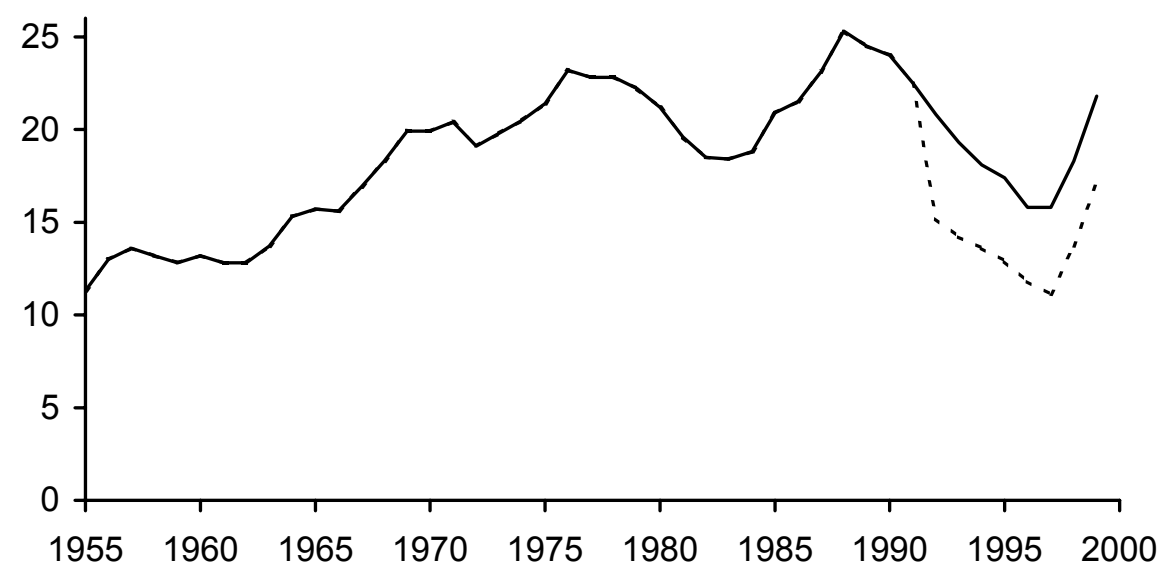

FIG. 2. - Days of paid sick leave according to the RFV and SAF databases combined, 195599.

Note: See Appendix for the construction of this series.

Here one can see a significant upward trend, indicating that the number of sick days increases by 0.18 days per annum. Due to the missing data for short-term spells at the beginning of the

\footnotetext{
4 The data are published in SAF (2000). The published data are arranged into rather broad groups of spell lengths. To obtain a finer grid, one has to use the original, unpublished data. These were given to us directly by SAF.
} 
period, one should not make too much of that trend, however. ${ }^{5}$ Still, this is the best data available for long time series. But before we proceed to the more reliable, shorter data series, we will take a look at the sickness benefit insurance in a long-term perspective.

\section{The Sickness Benefit Rules - A Brief Characterization}

A mandatory, government-financed sickness insurance system was introduced in 1955. Over the years, this system has been reformed a great number of times. Table 1 summarizes the changes in the compensation levels (replacement rates) from 1987 up to 2000.

Prior to 1987 , the system was too complicated to be summarized by a few numbers, like the ones in Table 1. For instance, before 1974 compensation was untaxed, which makes a comparison with later periods difficult. Also, compensation could vary depending on the day of the week or whether the insured person was married, had children etc. ${ }^{6}$ The important pre1987 changes are the following.

Before 1987 there was an initial waiting period; during the first day(s) of a sick spell compensation was zero. Between 1955 and 1966 this waiting period was three days, and in 1967 it was reduced to one day. In 1987 the waiting period was removed, and compensation was paid from the first day of a sickness period. ${ }^{7}$

Although the level of compensation thus varied across individuals and weekdays, the overall level was substantially raised on three occasions: in 1967, 1967 and 1974. In December 1987 the level was made uniform, and raised to 90 percent for everybody.

In addition to the public system, supplementary benefit systems developed as a result of negotiations between employers and trade unions. These systems were introduced gradually

\footnotetext{
${ }^{5}$ According to the SAF database, roughly 10 percent of all workdays lost in the 1990 s were due to one-day sickness spells. If the pattern was the same in the 1950s and 1960s, the curve in Figure 2 underestimates the true absenteeism for these decades by around 1.5 days. Adding 1.5 days to each year's figure for the period 19551973 and fitting a trend line to the thus adjusted time series of the whole time period still yields a significant upward slope: the number of sick days increases by 0.13 days per annum (standard error $=0.032$ ).

${ }^{6}$ Cf. Broberg (1973).

${ }^{7}$ In 1974-1987 it was possible to avoid the waiting period by reporting sick before midnight the preceding day (even if that day was a Sunday).
} 
for different professions and industries; by the mid-1970s they had become fairly uniform and covered virtually all employees.

In Table 1, the additional percentage of the wage covered by these systems are indicated to the right of the "+" sign. For example, the entry " $90+10$ " for the first day of absence during the December 1987 to February 1991 period means that from the first day of absence, the person received 90 percent of his or her regular wage from the public system and an additional 10 percent from the supplementary employer/union system.

Thus, there has been considerable variation in the sick leave compensation system since its inception some 45 years ago. ${ }^{8}$ This institutional variation is a great advantage in our context, since it increases the possibilities for identifying any behavioral effects of the system.

\section{(Table 1)}

\footnotetext{
8 Table 1 only gives the changes in the compensation levels. There have also been other changes, for example in the administrative rigor and the requirement of a certificate from a doctor as soon as the leave of absence exceeds a certain time span. For example, in October 1995 a number of measures were taken that tightened the qualification criteria for receiving long-term sickness benefits. Although these changes are difficult to quantify, we have tried to take some of them into account in our regressions reported below.
} 


\section{Table 1}

\section{Sick leave compensation as a share of the wage level, 1987-1999 (\%).}

\begin{tabular}{|c|c|c|c|c|c|c|c|c|c|}
\hline $\begin{array}{l}\text { Day of } \\
\text { sick } \\
\text { leave }\end{array}$ & $\begin{array}{r}1987.12- \\
1991.02\end{array}$ & $\begin{array}{r}1991.03- \\
1991.12\end{array}$ & $\begin{array}{r}1992.01- \\
1993.03\end{array}$ & $\begin{array}{r}1993.04- \\
1993.06\end{array}$ & $\begin{array}{r}1993.06- \\
1995.12\end{array}$ & $\begin{array}{r}1996.01 \\
- \\
1996.12 \\
\end{array}$ & $\begin{array}{r}1997.01 \\
- \\
1997.12 \\
\end{array}$ & $\begin{array}{r}1998.01 \\
- \\
1998.03 \\
\end{array}$ & 1998.04- \\
\hline 1 & $90+10$ & $65+10$ & $0+75$ & $0^{2}$ & $0^{2}$ & $0^{2}$ & $0^{2}$ & $0^{2}$ & $0^{2}$ \\
\hline $2-3$ & $90+10$ & $65+10$ & $0+75$ & $0+75$ & $0+75$ & $0+75$ & $0+75$ & $0+80$ & $0+80$ \\
\hline $4-14$ & $90+10$ & $80+10$ & $0+90$ & $0+90$ & $0+90$ & $0+75$ & $0+75$ & $0+80$ & $0+80$ \\
\hline $15-28$ & $90+10$ & $80+10$ & $80+10$ & $80+10$ & $80+10$ & $75+10$ & $0+75$ & $0+80$ & $80+10$ \\
\hline 29-90 & $90+10$ & $80+10$ & $80+10$ & $80+10$ & $80+10$ & $75+10$ & $75+10$ & $80+10$ & $80+10$ \\
\hline $91-365$ & $90+5$ & 90 & 90 & 80 & 80 & 75 & 75 & 80 & 80 \\
\hline $366-$ & $90+5$ & 90 & 90 & 80 & 70 & 75 & 75 & 80 & 80 \\
\hline
\end{tabular}

Note: ${ }^{1}$ Refers to calendar days and not to working days. ${ }^{2}$ The waiting period can be partly avoided after 1993 by reporting sick late in the day. The wage deduction will then be limited to a small part of the day (as little as $1 / 4$ ) when the sickness began.

The percentage to the right of the +-sign, when applicable, indicates the replacement rate emanating from supplementary schemes. Throughout the entire period the coverage of the public system has been capped, i.e., no coverage is provided above a certain income level (more than 90 percent of the wage-earners have consistently been below this level). In most cases, however, employers provide supplementary coverage for higher incomes.

A physician's certificate is always required in order to continue to receive benefits after the seventh calendar day of sickness. Generally, any physician of the patient's choice may issue the required certificate. The criteria became more stringent in October 1995 including a requirement for more thorough medical examinations for long-term cases. Source: Lidwall and Skogman Thoursie (2000) and SAF (2000). 


\section{Empirical Analysis}

\section{A. General Formulation}

The propensity to report sick can be affected by a number of variables. In order to see how the compensation level in the insurance system affects absenteeism, we have to control for, inter alia, the general health situation in the country, the age composition of the labor force, and the situation in the labor market.

A general dynamic regression (autoregressive distributed lag model) could be formulated as

$$
S_{t}=\alpha_{0}+\sum_{i=0}^{n} \alpha_{i} X_{t-i}+\beta \cdot R E F_{t}+\sum_{i=1}^{m} \gamma_{i} S_{t-i}+\varepsilon_{t}
$$

Here, $S_{t}$ is the average number of sick days per person in year $t$, using the corrected data of Figure 2. This model allows for flexibility in the dynamic structure since lagged values of $S$ are included as explanatory variables. Moreover, it makes it possible to distinguish between the short-run impact effect and the long-run effect of the introduction of different reforms.

The explanatory variable $X_{t}$ is a vector of variables that may affect absenteeism. These include

- The rate of unemployment; traditionally, the tightness of the labor market seems to have an impact on absenteeism (e.g., Leigh, 1985 and Arai and Skogman Thoursie, 2001).

- The general health condition in the population (measured by the mortality rate in the total population).

- The age composition of the population (measured by the fraction of the labor force aged 45-64).

- The labor force participation rate; the often proposed hypothesis is that a higher labor force participation will increase sickness absenteeism.

- The gender composition of the labor force (e.g., the percentage of the labor force that is female). For the time being, we disregard this aspect; later on in the paper, we will use a shorter time series with better data, and then we can address the issue in a more efficient way. 
The variable $R E F_{t}$ is a vector of dummy variables, describing the various reforms that have affected the sickness insurance system during the period 1955-99. From Table 1 we can see that Sweden has had at least 13 different sickness insurance systems ${ }^{9}$ since 1955 ; to these should be added changes in other parameters than the compensation level. These changes could be represented by a set of dummy variables. For example, let $R E F 63_{t}$ represent the 1963 reform, taking the value 0 for all years before 1963 and the value 1 for all $t \geq 1963$. However, some reforms were not implemented at the beginning of the year; for a reform implemented during a year, the dummy variable becomes a fraction for that year. Thus, since the 1987 reform was implemented on December 1 of $1987, R E F 87_{t}=0$ for all $t<1987, R E F 87_{t}=1 / 12$ for $t=1987$, and $R E F 87_{t}=1$ for $t>1987$.

The dummy variable methodology warrants some comments. Each reform, as described in Table 1, changes the individual's cost of being absent from work. Ideally, economists would like to estimate the sensitivity of individuals to changes in that cost, i.e., the price elasticity of absenteeism. This is in principle what the cross-section studies, referred to above, do; due to the existence of ceilings in the sick leave compensation, differences in tax situation, et cetera, there is considerable variation in the cost of absenteeism across individuals. Under one particular insurance system, for example the one prevailing in 1992, the cost sensitivity can thus be estimated. If one wants to use long time series, with many systems represented, individual cost data are difficult (or impossible) to obtain. And since individuals differ in many dimensions - for instance, with respect to income, or with respect to the length of the sickness spell - there is no one-dimensional measure of the change in the cost of being absent from work due to a particular reform.

Also, the matter of information is important. Some reforms seem to have been well known to the general public, and thus most people may have had a fairly accurate perception of the cost of calling sick at some dates. Other reforms, on the other hand, may have passed relatively unnoticed - and one might conjecture that the sheer number of reforms in the 1990s made it difficult for many people to keep informed of the current rules in a particular year. Thus, the perceived cost is not necessarily the same as the official cost shown in Table 1. Finally, many reforms may have implied changes in the strictness of administrative routines, as well as other measures not easily captured in the plain compensation levels of Table 1. By using dummies

\footnotetext{
${ }^{9}$ In practice, there are changes in the system taking place more or less continuously. Any grouping of these
} 
to represent the reforms, rather than trying to compute a measure of the perceived cost to the representative agent, we have tried to handle these complications in a simple and straightforward way.

Given that we have settled for the dummy variable methodology, we could in principle run a regression including all 13 systems shown in Table 1. This would mean using 12 reform dummies. However, given the limited number of observations, the numerous reforms and the fact that some of them were in place during a very brief period, including all reforms is bound to render the estimates imprecise. ${ }^{10}$ This is particularly true for the $1990 \mathrm{~s}$, when the reforms are so frequent that it is difficult to distinguish one from the other. Thus, it is necessary to exclude at least some of the reforms during the period in order to make the estimation feasible.

We have thus chosen to include all reforms that occurred before the 1990s, i.e., the 1963 , 1967, 1974, and 1987 reforms. As for the 1990s, almost any subset of reforms seem to be possible; a priori reasoning has however lead us to include the 1991 and 1998 reforms. The 1991 reform is the first reduction in compensation levels since the inception of the system in 1955. This is likely to be of major importance, since it constitutes a fundamental break with previous reforms. It is arguably the most hotly debated and criticized reform in the entire history of the Swedish sickness insurance system. The 1998 reform is also potentially important since it constitutes a new break; it entails the first increase in benefits since 1987.11

In addition to the reforms in Table 1, we have included an allegedly important reform implemented in 1995. There was no change in the compensation level then, but according to people working in the field, the routines in the whole social insurance system became more restrictive, and this (among other things) affected the propensity to call sick.

\footnotetext{
changes into "minor" and "major" changes must necessarily be somewhat subjective.

10 Lidwall and Skogman Thoursie (2000), report a regression on the same data (although not corrected for the under-reporting in 1992-1999) including almost all reform dummies. Their results are difficult to compare to ours, since their regression equation is static and does not have any explicitly dynamic structure, like our equation (1). They also include one additional reform (in 1985), which we choose not to include in Table 1, since it only affected a small subset of public-sector employees. In their regression most of the coefficients for the reform dummies turn out to be insignificant.

11 There were two reforms in 1998. Since there were only 3 months between them, they cannot be meaningfully distinguished in the data. We have therefore, somewhat arbitrarily, included only the first one in the regressions.
} 
There was also a potentially important reform in 1992, when the employers assumed the financial responsibility for the first two weeks of a sickness spell. Since there were only 9 months between the 1991 and 1992 reforms, it is difficult to distinguish their respective effects in the data. This is a general problem in the 1990s, when the reforms were so frequent that their effects cannot be accurately distinguished. Subsequent reductions in benefit levels are likely to be less important than the 1991 and 1992 reforms, since they are both smaller, more frequent, and mainly confirm the break in the previous trend towards more generous benefit levels.

We have thus settled for the following set of reform dummies: REF63, REF67, REF74, REF87, REF91, REF95, and REF98. In order to assess the robustness of this selection, we have also run regressions on this set supplemented by various combinations of one or two of the other omitted reform dummies (see Appendix).

Finally, estimating an equation like (1) raises the issue of causality. How does one, for example, know that the reform variable $R E F$ causes sick leave $S$, and not the other way around? For a causal interpretation of a regression coefficient, we must be able to tell a story that is reasonable, and the story behind the causation $R E F \rightarrow S$ sounds reasonable enough: generous compensation rules reduce the cost of being away from work, which makes people more likely to call sick. But there is also a story for the reverse causation, $S \rightarrow R E F$ : more people being sick means a higher pressure on the political system to make the benefit rules more generous, which in turn makes the politicians more likely to implement generous reforms. Which one of these stories is the correct one (in principle, both can be true) is an empirical question. But, there are indications that $R E F \rightarrow S$ is more plausible. For instance, if $S \rightarrow R E F$ were true, one would first observe an increase in the number of sick days, and then a reform would be implemented. But because of lags in the political decision process, it would be rather difficult for the incumbent government to implement a reform without any delay. Further, if $S \rightarrow R E F$ had a large explanatory power as compared to the alternative causality, the coefficients of our dummy variables would be insignificant. Since this is not the case (cf. section IV.B and IV.C), we consider the causation $R E F \rightarrow S$ more likely. 
B. Estimation Results for the Long Time Series

The econometric strategy used is to begin by formulating a general and statistically well specified model. This is done by estimating equation (1) and applying a set of diagnostic tests. Next, the overparameterized model is reduced in order to obtain a parsimonious representation, which is tested in order to make sure that the assumptions regarding its stochastic properties are fulfilled. To illustrate the degree of relevance of the various reforms, the dummies are kept in the final version even when they are insignificant. ${ }^{12}$

Before carrying out the regression analysis it is useful to consider the stochastic properties of the variables. In equation (1), $S_{t}$ enters in levels. The reason is that the number of sick days during a year is restricted to lie between 0 and 365. Thus, by definition the $S_{t}$ time series cannot have a unit root. But it is possible that $S_{t}$ displays local nonstationarity in our finite sample. In fact, testing $S_{t}$ for a unit root shows that it is stationary for the period 1970-1999, i.e., for most of the sample period but not for the whole period 1955-1999. However, by including the reform dummies of 1963 and 1967 nonstationarity was clearly rejected. ${ }^{13} \mathrm{We}$ thus proceed under the assumption that $S_{t}$ is stationary. ${ }^{14}$

As for the variables in the $X$ vector, the rate of unemployment (UNEMP) appears to be a stationary variable with a structural break in the beginning of the 1990s. This was confirmed by a unit root test that included the 1991 reform dummy.

Unfortunately, the mortality rate does not make as much sense as a proxy for general health as one would like. It would have been preferable to have a more direct measure of the general health status of the labor force, but unfortunately we have not managed to find any reasonable measure spanning our long time period. The mortality rate displays an upward trend, despite the fact that there is no obvious long-term deterioration in the general health condition of the

\footnotetext{
12 Ericsson, Campos and Tran (1990) give a good description of the general-to-specific methodology.

13 Ideally a procedure such as the one developed by Bai and Perron (1998) for testing for multiple structural changes should have been used. However, considering our small sample and the fact that the results were as expected, using augmented Dickey-Fuller tests seemed sufficient. The results of the unit root tests can be obtained from the authors upon request.

14 We also experimented by estimating the model including a deterministic time trend, but it turned out to be insignificant.
} 
population during that period. After some hesitation, we have chosen not to include that variable. ${ }^{15}$

Finally, neither the age composition of the labor force nor the labor force participation rate is stationary, and they do not appear to be cointegrated. Indeed, the age composition of the labor force does not even appear to be first-difference stationary. There is thus no reason to think that any of these two variables in levels, or linear combinations of them, should affect sick leave. In fact, they did not turn out to have any explanatory power in either levels or first differences. We have, therefore, chosen to run the regressions without the age composition of the labor force and without the labor force participation rate to get more power when doing the general-to-specific modeling and testing for misspecification et cetera. As a final check on our results, we tested whether the age composition of the labor force or the labor force participation rate entered the parsimonious models, but they turned out to be insignificant. ${ }^{16}$

The general model for the aggregate data was estimated for the period 1958-1999. It contained three lags of each variable, dummies for seven reforms and a constant. None of the diagnostic tests was significant, indicating that the model is statistically well specified (not reported). After removing insignificant variables we ended up with the parsimonious model. Table 2 reports the estimated coefficients and diagnostic test statistics. Statistically the estimated model appears well specified; there is no evidence of serial correlation ( $A R$ test), autoregressive heteroskedasticity ( $A R C H$ test), non-normal errors (Normality test) and regression mis-specification (RESET test). ${ }^{17}$ Moreover, the $F$-test for the reduction of the general to the parsimonious model is insignificant. The estimates reported in Table 2 turn out to be quite robust with respect to the inclusion of additional reforms during the $1990 \mathrm{~s}-$ see Appendix.

Let us look at the first column, denoted (a). First, we note that current-period unemployment is significant, ${ }^{18}$ with a negative sign, at the 5 percent level; as unemployment increases,

\footnotetext{
15 Given that the general health condition of the population is not correlated with the reforms, this omission does not give rise to any omitted variables bias. We see no a priori reason to expect any correlation of this kind.

${ }^{16}$ An anonymous referee suggested that we should include additional macroeconomic controls. Given the long time period the number of reasonable controls available is limited. However, we managed to collect the variable number of annual hours worked per person employed. When this variable was added to regressions (a) and (b) in Table 2, it turned out to be insignificant.

17 See Hendry (1995) on these tests.

18 Lagged values of unemployment were not significant.
} 
sickness absenteeism falls. This is a well-known observation, and it could have two explanations. One is a selection effect; in a recession, those who are most often sick are the first to be laid off. ${ }^{19}$ The other explanation is based on unemployment as a worker discipline device (Shapiro and Stiglitz, 1984). If marginal workers are more likely to have temporary contracts, procyclical absenteeism may be even stronger (Arai and Skogman Thoursie, 2001). With reliable cross-country data, those two hypotheses could in principle be tested against each other. In countries where job protection is strong, the employers have less freedom to choose which workers to be laid off. Thus one would expect that the negative effect of unemployment on the number of sick days is weaker in such countries than in countries with less job protection. ${ }^{20}$

Looking at the reform coefficients, we see that all but one are significant and have the sign that economic theory would predict. When benefits become more generous (like in 1963, 1967, 1974, 1987 and 1998) the number of sick days increase, and when the insurance system becomes more austere (in 1991 and 1995) the number of sick days fall. However, the 1991 reform should be the cause of some concern, since it is insignificant. We will return to that problem in a moment.

The coefficient of the $S_{t-2}$ term was insignificant and has been deleted in the final estimation, but the coefficients of the $S_{t-1}$ and $S_{t-3}$ terms were highly significant. The dynamic structure of the model makes it possible for us to distinguish between short-run and long-run effects of the reforms. Take the 1998 reform as an example. The estimated coefficient is 2.43 , which is the short-run effect. Since the coefficients of the $S_{t-1}$ and $S_{t-3}$ terms are 0.80 and -0.39 , respectively, we can easily compute the long-term effect of the 1998 reform as $2.43 /(1-(0.80$ $-0.39))=4.12$. Thus, while the reform is associated with an immediate increase in the number of sick days by 2.43 , the number eventually increases to 4.12 days.

Let us now return to the insignificant coefficient of the 1991 reduction in the sickness benefits. From the heated debate in the media when the reform was implemented, one would expect it to have a clear impact on sick leave behavior. Why the regression coefficient seems to tell another story probably lies in the dramatic events in the early 1990s, when the Swedish

\footnotetext{
19 However, they still can, and have the incentive to, report sick.

20 Sweden is among the countries which has had the strongest job protection mandates in the OECD area, see OECD (1994) and Davis and Henrekson (1999).
} 
economy was thrown into its deepest recession since the 1930s. Unemployment started to increase dramatically in 1991 and remained high for the rest of the decade. The UNEMP variable is thus highly correlated with the REF91 variable, and it is difficult to say how much one affects the number of sick days as opposed to the other. In fact, the 1991 reform was initiated by the Swedish government's sharply increasing budget deficits, which called for drastic reductions in government spending. Thus the changes in REF91 and UNEMP were both endogenous responses to a structural crisis hitting the Swedish economy, and one could say that the model represented by equation (1) is the reduced form of another, more general, model. The statistically correct approach would be to estimate the structural form of that model, but since economic and political theory has not yet told us what such a model would look like, this is an infeasible task.

In the absence of such a model, it is instructive to see what happens if we drop the UNEMP variable from the regression. The results of such a regression are reported in the second column, labeled (b), of Table 2. Here we see that the coefficient of REF91 now turns out to be significant, with at $t$-value of -1.96 .

Finally, we note that the dynamic aspects become more pronounced when we drop the unemployment term. According to the parameter estimates in column (b) of Table 2, the short-run effect of the 1991 reform was to reduce the number of sick days by 1.31 days. The long-run effect, however, was to reduce the number by $1.31 /(1-(0.91-0.42))=2.57$ days. Similarly, the short run effect of the more generous compensation level introduced in 1998 was to increase the number of sick days by 3.00 days, while the long-run effect was an increase by $3.00 /(1-(0.91-0.42))=5.88$ days. This indicates that the sickness insurance system could be a major determinant of the effective labor supply.

A word of caution is warranted in this context. As is seen in Figure 2, the number of sick days increased sharply in 1999. The reasons for this are debated; some people point at an alleged increase in the level of stress at the workplace. In our model formulation, however, there is no room for such explanations. In principle, one could add another explanatory variable to the model, but it is desirable that such a variable be observable; to simply include an ad hoc year dummy for 1999 is not satisfactory. While waiting for an alternative theory to explain the increase in the number of sick days in 1999, that increase might manifest itself in a high value of the estimated coefficient of the 1998 reform. 
Table 2

Effects of the reforms on the number of paid sick days per year using annual data, 1958-1999.

\begin{tabular}{|c|c|c|}
\hline Variable & (a) & (b) \\
\hline Constant & $\begin{array}{r}8.03 * * * \\
(5.87)\end{array}$ & $\begin{array}{r}6.41 * * * \\
(5.41)\end{array}$ \\
\hline$U N E M P_{t}$ & $\begin{array}{r}-0.33 * * \\
(-2.09)\end{array}$ & - \\
\hline REF63 & $\begin{array}{r}1.18 * * \\
(2.64)\end{array}$ & $\begin{array}{r}1.12 * * \\
(2.39)\end{array}$ \\
\hline REF67 & $\begin{array}{r}2.62 * * * \\
(4.35)\end{array}$ & $\begin{array}{r}2.07 * * * \\
(3.64)\end{array}$ \\
\hline REF74 & $\begin{array}{r}1.39 * * * \\
(3.49)\end{array}$ & $\begin{array}{r}1.19 * * * \\
(2.93)\end{array}$ \\
\hline REF87 & $\begin{array}{r}0.98 * \\
(1.97)\end{array}$ & $\begin{array}{l}0.96 * \\
(1.85)\end{array}$ \\
\hline REF91 & $\begin{array}{r}-0.03 \\
(-0.03)\end{array}$ & $\begin{array}{l}-1.31 * \\
(-1.96)\end{array}$ \\
\hline REF95 & $\begin{array}{r}-1.72 * * \\
(-2.42)\end{array}$ & $\begin{array}{r}-1.91 * * \\
(-2.59)\end{array}$ \\
\hline REF98 & $\begin{array}{r}2.43 * * * \\
(3.34)\end{array}$ & $\begin{array}{r}3.00 * * * \\
(4.12)\end{array}$ \\
\hline$S_{t-1}$ & $\begin{array}{r}0.80 * * * \\
(8.10)\end{array}$ & $\begin{array}{r}0.91 * * * \\
(10.25)\end{array}$ \\
\hline$S_{t-3}$ & $\begin{array}{r}-0.39 * * * \\
(-4.54) \\
\end{array}$ & $\begin{array}{r}-0.42 * * * \\
(-4.69) \\
\end{array}$ \\
\hline$R^{2}$ & 0.97 & 0.97 \\
\hline$A R 1-2 F(2,29)$ & $\begin{array}{r}0.73 \\
{[0.49]}\end{array}$ & $\begin{array}{r}0.80 \\
{[0.46]}\end{array}$ \\
\hline$A R C H 1 F(16,14)$ & $\begin{array}{r}0.04 \\
{[0.84]}\end{array}$ & $\begin{array}{r}0.28 \\
{[0.60]}\end{array}$ \\
\hline Normality $\chi^{2}$ & $\begin{array}{r}0.45 \\
{[0.93]}\end{array}$ & $\begin{array}{r}1.74 \\
{[0.42]}\end{array}$ \\
\hline Heteroskedasticity $F(16,14)$ & $\begin{array}{r}0.45 \\
{[0.93]}\end{array}$ & $\left.\begin{array}{r}0.61 \\
{[0.82}\end{array}\right]$ \\
\hline $\operatorname{RESET~F~}(1,30)$ & $\begin{array}{r}0.057 \\
{[0.81]}\end{array}$ & $\begin{array}{r}0.37 \\
{[0.54]}\end{array}$ \\
\hline $\begin{array}{l}F \text {-test for simplification of } \\
\text { general model, } F(4,26)\end{array}$ & $\begin{array}{r}0.72 \\
{[0.59]}\end{array}$ & \\
\hline
\end{tabular}

Note: $*, * *$ and $* * *$ denote significance at the 10,5 and 1 percent levels, respectively. $t$-statistics within parentheses. The following tests were implemented, serial correlation ( $A R$ test), autoregressive heteroskedasticity ( $A R C H$ test), non-normal errors (Normality test), residual heteroskedasticity test and regression mis-specification (RESET test); prob values for all diagnostic tests in square brackets. For further details, see Hendry (1995). 


\section{Estimation Results for Men and Women}

It is now time to look into the pattern of sick leave in more detail. From 1964, the unemployment data series distinguishes between men and women; we can thus run separate estimations for men and women and thereby obtain sharper estimates. The fact that the time series is now shorter is a disadvantage, but on the other hand the years that have been deleted are those where the number of sick days were somewhat inaccurately measured anyway. We estimate the same autoregressive model as before, but with separate estimates for men and women. The results are reported in Table $3 .{ }^{21} \mathrm{In}$ line with the discussion above we have chosen to delete the age variable from the regression altogether.

First we note that if unemployment is included among the explanatory variables (columns (a) in the table), the intercept for men and women do not differ significantly from one another. This is contrary to the common view, namely that women are more often sick than men. This observed discrepancy can thus be explained by the unemployment and reform variables. Note also that if we drop the UNEMP variable (columns (b) in the table) the conventional wisdom is restored: The intercept is larger for women than for men, since sick leave of women is more responsive to unemployment.

\footnotetext{
${ }^{21}$ Here, too, we tried to include the labor force participation rate among the explanatory variables, but that
} variable did not come out with a significant coefficient. 
Table 3

Effects of the reforms on the number of sick days, 1967-1999.

\begin{tabular}{|c|c|c|c|c|}
\hline \multirow[t]{2}{*}{ Variable } & \multicolumn{2}{|c|}{ Men } & \multicolumn{2}{|c|}{ Women } \\
\hline & (a) & (b) & (a) & (b) \\
\hline \multirow{2}{*}{ Constant } & $7.46^{* * *}$ & $6.58 * * *$ & $6.97 * *$ & $10.27^{* * *}$ \\
\hline & (4.08) & (4.27) & (2.67) & (4.11) \\
\hline \multirow{2}{*}{$U N E M P_{t-1}$} & -0.12 & - & $-0.93 * *$ & -- \\
\hline & $(-0.90)$ & & $(-2.78)$ & \\
\hline \multirow{2}{*}{$U N E M P_{t-2}$} & -- & -- & $1.48^{* * *}$ & -- \\
\hline & & & (3.37) & \\
\hline \multirow[t]{2}{*}{ REF74 } & 0.52 & 0.45 & 0.95 & $1.85 * * *$ \\
\hline & $(1.16)$ & $(1.03)$ & $(1.58)$ & (3.22) \\
\hline \multirow[t]{2}{*}{ REF87 } & -0.52 & -0.46 & $2.00 * *$ & $2.40 * *$ \\
\hline & $(-0.98)$ & $(-0.87)$ & $(2.53)$ & $(2.55)$ \\
\hline \multirow[t]{2}{*}{ REF91 } & -0.32 & -0.71 & 0.06 & -0.50 \\
\hline & $(-0.38)$ & $(-0.99)$ & $(0.07)$ & $(-0.55)$ \\
\hline \multirow[t]{2}{*}{ REF95 } & -0.71 & -0.95 & $-4.89 * * *$ & $-1.99 *$ \\
\hline & $(-0.89)$ & $(-1.27)$ & $(-3.87)$ & $(-2.00)$ \\
\hline \multirow[t]{2}{*}{ REF98 } & $1.78 * *$ & $1.92 * *$ & $2.78 * * *$ & $3.39 * * *$ \\
\hline & $(2.25)$ & (2.49) & (3.76) & (3.98) \\
\hline \multirow{2}{*}{$S_{t-1}$} & $1.03 * * *$ & $1.07 * * *$ & $0.89 * * *$ & $0.97 * * *$ \\
\hline & (9.33) & (10.57) & (7.64) & (8.07) \\
\hline \multirow[t]{2}{*}{$S_{t-3}$} & $-0.40 * * *$ & $-0.41 * * *$ & $-0.32 * *$ & $-0.53 * * *$ \\
\hline & $(-4.07)$ & $(-4.16)$ & $(-2.66)$ & $(-4.23)$ \\
\hline$R^{2}$ & 0.94 & 0.94 & 0.97 & 0.95 \\
\hline \multirow[t]{2}{*}{$A R 1-2 F(2,29)$} & 0.097 & 0.19 & 0.66 & 0.55 \\
\hline & {$[0.90]$} & {$[0.83]$} & {$[0.53]$} & {$[0.58]$} \\
\hline \multirow[t]{2}{*}{$A R C H 1 F(16,14)$} & 0.035 & 0.030 & 0.63 & 0.26 \\
\hline & {$[0.85]$} & {$[0.86]$} & {$[0.44]$} & {$[0.62]$} \\
\hline \multirow[t]{2}{*}{ Normality $\chi^{2}$} & 3.25 & 2.41 & 0.84 & 0.59 \\
\hline & {$[0.20]$} & {$[0.30]$} & {$[0.66]$} & {$[0.75]$} \\
\hline Heteroskedasticity & 0.33 & 0.49 & 0.61 & 0.94 \\
\hline$F(\mathrm{x}, \mathrm{y}) \#$ & {$[0.96]$} & {$[0.89]$} & {$[0.79]$} & {$[0.54]$} \\
\hline \multirow[t]{2}{*}{$\operatorname{RESET~F}(1,22 / 23)$} & 0.31 & 0.75 & 0.0011 & 0.023 \\
\hline & {$[0.58]$} & {$[0.40]$} & {$[0.97]$} & {$[0.88]$} \\
\hline$F$-test for simplification & 0,58 & & 1.03 & \\
\hline of general model & {$[0.68]$} & & {$[0.40]$} & \\
\hline
\end{tabular}

Note: $*, * *$ and $* * *$ denote significance at the 10,5 and $1 \%$ levels, respectively. $t$-statistics within parentheses. \#The degrees of freedom vary across models. See Table 2 for definitions of the diagnostic tests.

Third, we see that all reform variables except REF98 have insignificant coefficients in the regression for men - and this holds regardless of whether we include UNEMP or not. For women, on the other hand, most reform variables have significant coefficients of the expected 
sign. This holds both if we include and exclude the $U N E M P$ variable. Thus, women seem to be more sensitive to economic incentives than men. This result conforms to the standard result in the labor supply literature. For example, Aronsson and Walker (1997, tables 5.2 and 5.3) review a number of empirical studies showing that female labor supply is more sensitive than male labor supply to the after-tax wage rate. ${ }^{22}$ It is however in stark contrast to the results regarding female sick leave behavior by Johansson and Brännäs (1998), and by Broström, Johansson and Palme (2001). These authors have estimated quite different models of sick leave, based on cross-section individual Swedish data for a few years only, and they report that women are less sensitive than men to changes in the cost (i.e., the compensation level) of being absent from work. ${ }^{23}$

Further, we see that contemporaneous as well as lagged unemployment is insignificant in the estimation for men, while first and second lags of unemployment are significant for women. Note also that although the first lag coefficient is negative, as expected, the second lag coefficient is positive.

A fourth observation is that the discrepancy between the short-run and the long-run effects seem to be stronger in Table 3 than in Table 2. Whether this is due to the long-run effects having increased over time, or whether using separate estimates for men and women, is difficult to tell. In any event, while the short-run effect of the 1998 reform was to increase the number of sick days for men by 1.78 days (1.92 if we drop the UNEMP variable) the long-run effect is $1.78 /(1-1.03+0.40)=4.81$ days $(5.65$ days if we drop the $U N E M P$ variable $)$. For women, the short-run effect of 2.78 days (3.39 without $U N E M P$ ) corresponds to a long-run effect of $2.78 /(1-0.89+0.32)=6.46$ days $(6.16$ without $U N E M P)$. Here, too, the qualification that we do not yet know whether the sharp increase in absenteeism in 1999 really was the consequence of the 1998 reform, or whether there was another cause, still applies.

\section{A Panel Data Analysis of the Effects of the 1987 and 1991 Reforms}

In the previous section we saw that even using annual time-series data one could, in most cases, detect large and significant effects on sick leave of changes in the benefit system.

\footnotetext{
22 See also the survey by Killingsworth and Heckman (1986).
} 
Perhaps somewhat surprisingly, we cannot find consistently negative effects of the 1991 reduction in sickness benefits. As already noted, one reason for this could be that the 1991 reform coincided with the onset of a deep economic crisis, and that the reform was instituted in response to the economic crisis. Moreover, given that we only have annual data and that the 1990s are characterized by numerous changes of the system, there is also likely to be a lack of degrees of freedom.

Fortunately, there are data available for the period 1983-91 that permit us to obtain sharper estimates of the effects of the 1987 and 1991 reforms. During this period the National Insurance Board (RFV) collected quarterly data covering all paid sick leave in Sweden. ${ }^{24}$ These sick leave data are also available on a regional basis (27 regions), which increases the number of degrees of freedom tremendously. However, no such high quality disaggregated data is available after 1991, since the public system gives no coverage for the first two weeks from 1992 (four weeks in 1997-98) and the employers have no incentives to report sick leave accurately to the National Insurance Board. Nevertheless, the data at hand are sufficient to assess the effects of the 1987 and 1991 reforms in greater detail.

As dependent variables we use the number of sick days per quarter $(D A Y S)$ and the number of sick leave spells per quarter (SPELLS). Among the regressors we include regional and seasonal dummies. We do not have separate data on sick leave for males and females. Instead we control for a likely gender effect by including the share of women in the labor force in each region (FEMALE) among the regressors. UNEMP measures the rate of unemployment in each region. Other control variables are the labor force participation rate $(P A R T)$ and the share of the employed that work more than 35 hours per week (INTENSITY), which is used as a measure of work intensity.

The two reforms took place at the beginning of December and March, respectively; hence the reform dummies will take the value $1 / 3$ in the reform quarter and unity thereafter. Both reforms, and in particular the 1991 reform, were preceded by a great deal of publicity and public debate, and as a result the immediate effect may differ from the long-run effect. ${ }^{25}$

\footnotetext{
${ }^{23}$ In another empirical study of sick leave in Sweden, using cross-section data, Johansson and Palme (2000), do not find any clear differences between men and women with respect to the sensitivity to the cost of sick leave. 24 During the period 1983-88 monthly data was collected, but in order to cover the whole period through 1991 quarterly data has to be used.

${ }^{25}$ See Lidwall and Örnhall (1991) for a more thorough discussion.
} 
Hence, we use a specification that allows for a different effect during the actual reform quarter in 1987 and 1991 as compared to the long-run effect. This is achieved by including reform quarter dummies (REFQ87 and REFQ91), which take the value 1 in Q4 of 1987 and Q1 of 1991, respectively, and 0 in all other quarters.

Our data set consists of observations from 27 regions for 36 quarters, hence a (possibly dynamic) panel estimation is called for. We begin by estimating the effect on DAYS. A leastsquares regression with a White heteroskedasticity consistent variance-covariance matrix is reported in column (a) of Table 4. Here we obtain very strong and significant effects of the two reforms. It is also clear that the reform quarter dummies need to be included. However, it is evident from the $D W$-statistic that the residuals are autocorrelated. The simplest way to correct for this problem is to model the residual as an $A R 1$-process. The results from this estimation are reported in column (b). ${ }^{26}$ The two reforms still come through as having a significant effect and the estimated effect is quantitatively important. The 1987 reform is estimated to have increased the number of annual sick days by roughly $1.1(0.27 \mathrm{x} 4)$ days per year. Compared to an average of 23 days of sick leave per insured in 1987, this implies an increase of roughly five percent as a result of the reform. The 1991 reform is estimated to have reduced the annual number of sick days by $0.8(0.19 \times 4)$ days, which corresponds to a reduction of 3.3 percent relative to the 1990 level.

An alternative, and more general, way to account for the dynamic structure is to estimate a dynamic panel (see Baltagi, 1995). It turns out that all the dynamics we need, to obtain wellbehaved residuals, is to include a one-period lag of the dependent variable among the regressors. When one has to model an episode that has an impact on the dependent variable for one period only, a lag of this impact dummy has to be included when a lag of the dependent variable is included among the regressors. Why this is so is shown in the Appendix.

In column (c) we report such a dynamic regression while only correcting for heteroskedasticity using White's (1980) method. However, the variance-covariance matrix indicates that residuals are highly correlated across regions, which means that a GLS with estimated cross-section residual covariance matrix can increase the efficiency of the estimation. This regression is reported in column (d). 
According to the dynamic panel estimation, the 1987 reform has the expected positive effect on the number of sick days, although it should be noted that the quantitative effect is found to be rather small. The 1991 reform has a significantly negative effect on sick leave. The first quarter effect is very strong, indicating an immediate drop of roughly four days per year or 20 percent relative to the 1990 level. The permanent effect of the 1991 reform is found to be smaller, being in the order of one day per year. Thus, the coefficient of $R E F Q 91$ indicates a fair amount of overshooting, but the coefficient of $R E F Q 91_{t-1}$ indicates that this initial effect is reverted after one period. A plausible explanations for this pattern may be that the reduced compensation level in 1991 was highly publicized and hotly debated in the media at the time, but that the effect of this debate on actual behavior faded rather quickly.

\footnotetext{
${ }^{26}$ In a more flexible specification we also allowed for different seasonal effects for each region and different $A R I$-processes across regions (available upon request). The results are very similar, which can be seen as an indication that the $A R 1$-result is very robust.
} 


\section{Table 4}

Effects of the 1987 and 1991 reforms on the number of paid sick days per quarter using regional and quarterly data for the 1983-91 period.

\begin{tabular}{lrrrr}
\hline Variable & $(\mathrm{a})$ & $(\mathrm{b})$ & $(\mathrm{c})$ & $(\mathrm{d})$ \\
\hline DAYS & -- & -- & $0.66 * * *$ & $0.67 * * *$ \\
& & & $(24.57)$ & $(41.42)$ \\
PART & & & & \\
& $-0.41 * * *$ & 0.0095 & $-0.014 *$ & $-0.01 * * *$ \\
INTENSITY & $(-3.35)$ & $(0.79)$ & $(-1.85)$ & $(-9.56)$ \\
& 0.0070 & -0.016 & $-0.029 * * *$ & $-0.025 * * *$ \\
FEMALE & $(0.67)$ & $(-1.35)$ & $(-3.22)$ & $(-11.81)$ \\
& $0.091 * * *$ & 0.028 & $0.036 * * *$ & $0.034 * * *$ \\
UNEMP & $(6.00)$ & $(1.48)$ & $(2.91)$ & $(12.66)$ \\
& $-0.24 * * *$ & $-0.075 * * *$ & $-0.083 * * *$ & $-0.067 * * *$ \\
REF87 & $(-12.70)$ & $(-3.84)$ & $(-5.25)$ & $(-20.59)$ \\
& $0.43 * * *$ & $0.27 * * *$ & $0.16 * * *$ & $0.14 * * *$ \\
REFQ87 & $(10.01)$ & $(4.42)$ & $(4.50)$ & $(4.97)$ \\
REFQ87 & $0.29 * * *$ & $0.29 * * *$ & $0.16 * * *$ & $0.17 * * *$ \\
& $(5.71)$ & $(7.34)$ & $(4.17)$ & $(2.61)$ \\
REF91 & -- & -- & $-0.35 * * *$ & $-0.26 * * *$ \\
REFQ91 & & & $(-7.85)$ & $(-3.90)$ \\
REFQ91 & $-0.19 * * *$ & $-0.19 * *$ & $-0.26 * * *$ & $-0.16 * * *$ \\
& $(-2.95)$ & $(-2.26)$ & $(-5.74)$ & $(-3.25)$ \\
AR1 & $-0.78 * * *$ & $-0.95 * * *$ & $-0.92 * * *$ & $-1.07 * * *$ \\
& $(-11.28)$ & $(-19.99)$ & $(-16.77)$ & $(-16.15)$ \\
Adj. $R^{2}$ & -- & -- & $0.81 * * *$ & $0.66 * * *$ \\
DW & & & $(8.58)$ & $(8.55)$ \\
No. of obs. & -- & $0.75 * * *$ & -- & -- \\
\hline
\end{tabular}

Note: $*, * *$ and $* * *$ denote significance at the 10,5 and $1 \%$ levels, respectively. $t$-statistics within parentheses. Estimates of the regional and quarterly dummies are not reported. In the GLS estimations we allow for different seasonal effects across counties 


\section{Table 5}

Effects of the 1987 and 1991 reforms on the number of sickness spells per quarter using regional and quarterly data for the $1983-91$ period.

\begin{tabular}{lrr}
\hline Variable & $(\mathrm{a})$ & $(\mathrm{b})$ \\
\hline PART & 0.00063 & $0.00045 * * *$ \\
& $(0.41)$ & $(2.69)$ \\
INTENSITY & $-0.0065 * * *$ & $-0.0054 * * *$ \\
& $(-5.49)$ & $(-32.40)$ \\
FEMALE & -0.0024 & $-0.0021 * * *$ \\
& $(-1.29)$ & $(-9.51)$ \\
UNEMP & 0.00042 & $0.00069 * * *$ \\
& $(0.22)$ & $(3.71)$ \\
REF87 & $0.064 * * *$ & $0.067 * * *$ \\
& $(13.96)$ & $(16.23)$ \\
REFQ87 & $-0.018 * * *$ & -- \\
REF91 & $(-3.14)$ & \\
& $-0.13 * * *$ & $-0.13 * * *$ \\
REFQ91 & $(-26.67)$ & $(-18.27)$ \\
& -0.0039 & -- \\
\hline Adj. $R^{2}$ & $(-0.62)$ & \\
DW & 0.81 & 0.80 \\
No. of obs. & 1.99 & 1.97 \\
\hline
\end{tabular}

Note: Estimates of the regional and quarterly dummies are not reported. In the SUR-estimation (b) we allow for different seasonal effects and correlated residuals across regions. In both regressions we correct for heteroskedasticity using White's (1980) method.

The quarterly data set has the further advantage that we can explore the effect of changes in the benefit level on one other aspect of sick leave, namely, the number of sick leave spells per time period. A change in the number of sick leave days results from the combined effect of changes in the average number of sick leave days per spell of sickness and the average number of sick leave spells per person. The 1991 reform disproportionately increased the cost of sick leave during the first three days, while the reduction was much smaller after the third day. Hence, if economic incentives are important, we would a priori expect a stronger effect on SPELLS than on DAYS. In Table 5 we report two regressions with SPELLS as the dependent variable. First, we may note that there is no autocorrelation in the residuals, so no lagged dependent variable is needed. In column (a) we report a heteroskedasticity-consistent least squares estimation, while column (b) reports a panel estimation using the SUR method. Using the latter (preferred) method the reform quarter dummies can be excluded without causing any econometric problems. Looking at regression (b), we can note that we find the 
expected positive effect on the number of spells after the 1987 reform, but even more importantly, we find a highly significant and quantitatively very large drop in the number of spells of sickness following the 1991 reform. An estimated drop in SPELLS of 0.52 (4 x 0.13 ) per year amounts to a drop of 23 percent relative to the 1990 level of an average 2.3 spells per year per insured. 27

Thus, short-term sick leave decreased far more than long-term sick leave. This reinforces the conclusion that the benefit level is an important determinant of sick leave behavior: the 1991 reform reduced compensation the most for sick leave of short duration, and should there be an effect, one would a priori expect larger effects on behavior for sick leave spells of short duration.

\section{Conclusions}

In this paper we have examined whether the level of sick leave compensation affects sick leave behavior. In contrast to earlier studies we have used aggregate data on average sick leave absence. The study has covered Sweden from 1955 to 1999. During this period the compensation level was changed on numerous occasions both upward and downward, which provides us with a number of natural experiments for empirical testing. According to our regression analyses there appears, in most cases, to be strong effects on sick leave behavior from changes in sick leave compensation levels. When the insurance system is made more generous, the aggregate number of sick days increases, and when the system is made more austere, the number falls. We also find clear differences across gender; in general, the sick leave behavior of women is found to be more sensitive to economic incentives than that of men.

The strong effects of changes in the compensation level are also apparent in our complementary panel study using quarterly data for the period 1983-91. The estimated effect of both the 1987 and 1991 reforms have the expected sign and are highly significant. Here it is particularly noteworthy that the number of sickness spells fell dramatically following the 1991 reform, when the reduction of compensation for the first few days of sick leave was particularly large.

\footnotetext{
27 A similar result is reported by Johansson and Palme (1996) who find a sharp drop in the number of short-term sickness spells between 1990 and 1991, while the number of spells exceeding three months actually increase.
} 
The interpretation of the significant unemployment effect raises a number of interesting issues. A simple interpretation is that it provides indirect evidence of the Shapiro and Stiglitz (1984) proposition that unemployment could function as a "worker discipline device". A different interpretation is that major changes in the rules of the sickness insurance system tend to coincide in time with marked business-cycle phenomena. A clear-cut example is the deep Swedish recession that started in 1991, which caused unemployment to rise sharply and public-sector finances to deteriorate, thereby forcing the government to cut down on various welfare schemes including the sickness insurance. Endogenizing policy shifts, and trying to decompose the unemployment effect into these two mechanisms, seems like an interesting issue, although such a task is beyond the scope of the present paper.

The partial nature of our analysis should be pointed out. Our empirical results show clearly that a reduction in the sickness benefits is associated with fewer sick days. This may however be counteracted by other behavioral responses, for example an increased tendency to early retirement. Such a response could be particularly relevant in higher age groups, and an indepth study of the interaction between different welfare systems stands out as a promising avenue for future research. 


\section{Appendix A}

\section{Data description, variable definitions and statistical sources}

\begin{tabular}{|c|c|c|}
\hline Variable & Definition & Source \\
\hline \multicolumn{3}{|c|}{ Dependent variables } \\
\hline$D A Y S$ & $\begin{array}{l}\text { Average number of days of sickness per } \\
\text { time period per insured } \dagger\end{array}$ & $\begin{array}{l}\text { National Insurance Board, SAF } \\
(2000)\end{array}$ \\
\hline SPELLS & $\begin{array}{l}\text { Average number of spells of sickness } \\
\text { per time period per insured }\end{array}$ & National Insurance Board \\
\hline \multicolumn{3}{|c|}{ Explanatory variables } \\
\hline MORT & $\begin{array}{l}\text { Number of deaths per } 100,000 \text { in the } \\
\text { total population }\end{array}$ & Statistics Sweden \\
\hline$A G E$ & Share of the labor force aged $45-64(\%)$ & Statistics Sweden \\
\hline UNEMP & $\begin{array}{l}\text { Open unemployment as a share of the } \\
\text { labor force }(\%)\end{array}$ & Statistics Sweden \\
\hline$L F P$ & $\begin{array}{l}\text { Share of women or men aged } 16-64 \text { in } \\
\text { the labor force }(\%)\end{array}$ & Statistics Sweden \\
\hline FEMALE & $\begin{array}{l}\text { Share of women in the labor force at the } \\
\text { regional level }(\%)\end{array}$ & Statistics Sweden \\
\hline$P A R T$ & Labor force participation rate $(\%)$ & Statistics Sweden \\
\hline INTENSITY & $\begin{array}{l}\text { Share of employed working }>35 \text { hours } \\
\text { per week }\end{array}$ & Statistics Sweden \\
\hline Reform dummies & See text & \\
\hline
\end{tabular}

Note: Depending on the context the variable is either annual or quarterly, and in the latter case it applies to the regional level.

$\dagger$ After 1991 the National Insurance Board has no information about the number of sick days during the first two weeks of a sickness spell (four weeks during the period 1997.01-1998.03). In order to correct for this we have constructed a new annual data series using data from SAF (2000) on sick leave as a percentage of contracted working hours during the period when the compensation is paid by the employer. The SAF data only covers the private sector and in order to get a figure for the whole economy we assume that behavior is identical in the private and public sectors. The SAF data contains detailed information on the percentage of the contracted number of workdays lost due to sick leave. In particular, it contains information on the fraction of sick leave attributable to the first two (or four) weeks of a sickness spell. This fraction can be translated into a number of working days lost, which in turn is added to the number of days in the RFV database. In order to translate the percentage measure into the number of working days, we assume that the annual number of working days is 223 ( $52 \times 5$ weekdays minus 25 days of paid vacation minus 12 days of paid holidays).

\section{Appendix B}

\section{The robustness of the estimates}

In the 1990s, the reforms are very frequent, and thus there is strong multicollinearity among the corresponding dummy variables. Including all reforms in the regression is therefore not meaningful; in the regressions reported in Table 2, we have not included the following reforms: REF92, REF93(2), REF96, REF97, and REF98(2). Some of these could, however, be included in order to illustrate the robustness of the estimates reported in Table 2.

We delete the reforms that are closer than one year to the reforms included in Table 2, i.e., we delete REF92 and REF98(2). Further, when choosing between REF93(1) and REF93(2), we choose to drop the latter. Of the remaining reforms dummies, we form all conceivable combinations of one or two additional reform dummies, i.e., we form the six sets (REF93), 
(REF96), (REF97), (REF93 + REF96), (REF93 + REF97) and (REF96 + REF97).

Supplementing the equation reported in Table 2 with each one of these six sets of additional explanatory variables yields six new regression results. None of the variables REF93, REF96 and REF97 obtain significant coefficients, in any combination. Including them, however, affects the coefficients of other variables. The effects of these inclusions are summarized in the table below, where the figures within square brackets represent the ranges of the estimate coefficients, and the asterisks represent the significance levels of the new estimates of the variables in Table 2. As before, column (a) reports the estimates including the UNEMP variable, while column (b) represents the estimates without it.

\begin{tabular}{lrr}
\hline Variable & $(\mathrm{a})$ & $(\mathrm{b})$ \\
\hline Constant & {$[7.86,8.24] * * *$} & {$[6.30,7.08] * * *$} \\
UNEMP & {$[-0.42,-0.31] 0, * *$} & - \\
REF63 & {$[1.17,1.19] *, * *$} & {$[1.11,1.17] * *$} \\
$R E F 67$ & {$[2.57,2.70] * * *$} & {$[2.03,2.29] * * *$} \\
$R E F 74$ & {$[1.35,1.42] * * *$} & {$[1.17,1.39] * * *$} \\
$R E F 87$ & {$[0.90,1.00] * * *$} & {$[0.94,1.09] *, * *$} \\
$R E F 91$ & {$[-0.05,0.07]$} & {$[-1.27,-0.83] 0, *$} \\
$R E F 95$ & {$[-4.47,-1.72] 0, * *$} & {$[-4.44,-1.65] 0, *$} \\
$R E F 98$ & {$[1.94,2.43] *, * *$} & {$[2.48,2.96] * * *$} \\
$S_{t-1}$ & {$[0.79,0.81] * * *$} & {$[0.87,0.91] * * *$} \\
$S_{t-3}$ & {$[-0.40,-0.38] * * *$} & {$[-0.43,-0.42] * * *$} \\
\hline
\end{tabular}

The table should be read as follows. For instance, for REF74, in column (b), the coefficient estimates ranged between a minimum of 1.17 (when we included REF97 in addition to the reforms included in Table 2) and a maximum of 1.39 (when we included REF93 and REF96). The three stars indicate that all estimates of the $R E F 74$ coefficient were significant at the $1 \%$ level. For $R E F 91$, the estimates are less robust; they range between -1.27 (when we include $R E F 93$ ) and -0.83 . The " $0, * *$ " indicate that the significant level ranges from zero (for the combinations (REF93), (REF93 + REF96), and (REF93 + REF97)) to 10\% (for the combinations (REF96), (REF97), and (REF96 + REF97)).

The conclusion is that most of the coefficients reported in Table 2 are very robust to additional explanatory variables. All reform dummies prior to the 1990s are virtually unaffected by whatever combination of additional explanatory variables we include. Also, the $R E F 98$ coefficient turns out to be robust, while there is some ambiguity regarding $R E F 91$ and REF95. Additional estimations substituting REF92 for REF91, and REF96 for REF95, indicate that it is very difficult to discriminate between these variables when using annual data.

\section{Appendix C}

Modeling an impact dummy when the lagged dependent variable is among the regressors

To remove a single outlier a dummy that takes the value one in that period and zero otherwise is sufficient if there are no lags of the dependent variable among the regressors. Otherwise, as 
a general rule, as many lags of the impact dummy as lags of the dependent variable need to be included. Suppose that we do not insert the lag of the dummy as in:

$$
y_{t}=\alpha+\beta_{1} y_{t-1}+\beta_{2} x_{t}+\beta_{3} x_{t-1}+\beta_{4} D_{t}+\varepsilon_{t}
$$

where $\varepsilon_{t}$ is iid and $D_{t}$ takes the value 1 only at $t=T$. In (A1), which includes no lag of the dummy, the impact effect of the outlier is $\beta_{4}$ in period $T, \beta_{1} \beta_{4}$ in period $T+1, \beta_{1}^{2} \beta_{4}$ in period $T+2$, and so forth. Therefore, this model is not appropriate if we want to capture the effect of an episode that only has a one-period impact. The appropriate model in this case is:

$$
y_{t}=\alpha+\beta_{1} y_{t-1}+\beta_{2} x_{t}+\beta_{3} x_{t-1}+\beta_{4} D_{t}+\beta_{5} D_{t-1}+\varepsilon_{t}
$$

Model (A2) is flexible enough to allow for the episode to have an impact in one period only. Moreover, it nests (A1), so the estimation of (A2) is fully in line with the general-to-specific methodology (Hendry, 1995). Incidentally, (A2) is the unrestricted version of the following model:

$$
y_{t}=a+b_{1} x_{t}+b_{2} D_{t}+u_{t}
$$

where $u_{t}$ is $\mathrm{AR}(1)$. Thus (A2) nests both (A1) and (A3). (A3) is the model used in column (b) of Table 4.

\section{References}

Arai, Mahmood and Skogman Thoursie, Peter. "Incentives and Selection in Cyclical Absenteeism." Working Paper no. 167. Stockholm: FIEF, 2001.

Aronsson, Thomas and Walker, James R. "The Effects of Sweden's Welfare State on Labor Supply Incentives.” In The Welfare State in Transition, edited by Richard B. Freeman, Robert Topel and Birgitta Swedenborg. Chicago: University of Chicago Press, 1997.

Bai, Jushan and Perron, Pierre. "Estimating and Testing Linear Models with Multiple Structural Changes." Econometrica 66 (January 1998): 47-78.

Baltagi, Bagi. Econometric Analysis of Panel Data. New York: John Wiley and Sons, 1995.

Barmby, Tim; Orme, Chris and Treble, John. "Worker Absenteeism. An Analysis Using Micro Data." Economic Journal 101 (March 1991): 214-229.

Barmby, Tim; Orme, Chris and Treble, John. "Worker Absence Histories: A Panel Data Study." Labour Economics 2 (March 1995): 53-65.

Broberg, Rolf. Så formades tryggheten: Socialförsäkringarnas historia 1946-1972. Stockholm: Försäkringskasseförbundet, 1973.

Broström, Göran; Johansson, Per and Palme, Mårten. "Causal Effects of Economic Incentives on Absence from Work: A Duration Analysis Using Fixed Effects.” Mimeo. Department of Economic Statistics, Stockholm School of Economics. 2001

Davis, Steven J. and Henrekson, Magnus. "Explaining National Differences in the Size and Industry Distribution of Employment." Small Business Economics 12 (February 1999): 5983. 
Drago, Robert and Wooden, Mark. "The Determinants of Labor Absence: Economic Factors and Workgroup Norms across Countries." Industrial and Labor Relations Review 45 (July 1992): 764-778.

Ericsson, Neil R., Campos, Julia and Tran, Hong-Ahn. "PC-GIVE and David Hendry's Econometric Methodology." Revista de Econometria 10, no. 1 (1990): 7-117.

Gilleskie, Donna B. "A Dynamic Stochastic Model of Medical Care Use and Work Absence." Econometrica 66 (1998): 1-45.

Hendry, David F. Dynamic Econometrics. Oxford: Oxford University Press, 1995.

Johansson, Per and Brännäs, Kurt. "A Household Model for Work Absence." Applied Economics 30 (November 1998): 1493-1503.

Johansson, Per and Palme, Mårten. "Do Economic Incentives Affect Work Absence? Empirical Evidence Using Swedish Micro Data.” Journal of Public Economics 59 (February 1996): 195-218.

Johansson, Per and Palme, Mårten. "Assessing the Effect of Public Policy on Worker Absenteeism.” Journal of Human Resources 37 (Spring 2002), 381-409..

Killingsworth, Mark R. and Heckman, James J. "Female Labor Supply: A Survey." In Handbook of Labor Economics, Vol. 1. edited by Orley Ashenfelter and Richard Layard, Amsterdam: North-Holland, 1986.

Leigh, J. Paul. "The Effects of Unemployment and the Business Cycle on Absenteeism." Journal of Economics and Business 37 (May 1985): 159-170.

Lidwall, Ulrik and Örnhall, Sara. "Sjukpenningreformens effekter på sjukfrånvaron med hänsyn tagen till arbetsmarknadssituationen - En analys av reformerna 1987 och 1991". Term paper. Department of Economics, Stockholm University, 1991

Lidwall, Ulrik and Skogman Thoursie, Peter. "Sickness Absence and Disability Pensioning during the Last Decades." In Work Life and Health in Sweden, edited by Staffan Marklund. Stockholm: The National Institute for Working Life and The National Board of Occupational Safety and Health, 2000

OECD. "Labor Standards and Economic Integration." OECD Employment Outlook, July (1994), 137-166.

SAF. Tidsanvändning år 1999. Stockholm: SAF Förlagsservice 2000.

Shapiro, Carl and Stiglitz, Joseph E. "Equilibrium Unemployment as a Worker Discipline Device." American Economic Review 74 (June 1984): 433-444.

White, Herbert. "A Heteroskedasticity-Consistent Covariance Matrix Estimator and a Direct Test for Heteroskedasticity”. Econometrica 48 (1980), 817-838. 